\title{
Somogy megye futóbogarainak (Coleoptera: Carabidae) katalógusa
}

\author{
HORVATOVICH SÁNDOR
}

\begin{abstract}
Horvatovich S.: Catalogue of the carabid beetles (Coleoptera: Carabidae) of Somogy county.
Abstract: 261 carabid species are listed from Somogy county. This number represents 53 percentage of the Hungarian carabid fauna. Three nature conservation areas were intensively researched: the Dráva region, the Boronka region and the Zselic Downs. For the first time, seven species (Carabus marginalis, Bembidion clarkii, Bembidion doris, Bembidion starki, Trechus obtusus, Acupalpus brunnipes, Europhilus scitulus) have been found in the Hungarian carabid fauna in Somogy county.
\end{abstract}

\section{Bevezetés}

Az elsó Somogy megyei, megbízható bogár adat Darányból származik Dudich Endre gyúutéséból (Csııı, 1946), aki 1932 szeptember 12-én a darányi legeló gémeskútjának vályújából gyújtötte a Carabus marginalis Fabricius, 1794 elsô magyarországi példányát. Ez a bogárfaj a jelenlegi ismereteink szerint is nagyon nagy ritkaság, elterjedése hazánkban egyetlen bakonyi lelóhely (Kutasi Csaba szóbeli közlése) kivételével Külső-Somogy homokterületeire korlátozódik.

Csiki Ernó elóbb említett Kárpát-medencei futóbogár-monográfiája tizegynéhány fajt említ Siófok lelóhellyel. Ezek az adatok azonban azért nem megbizhatóak, mert a Lichtneckert gyújteményból származnak és erról a gyưjtôról bebizonyosodott, hogy a Siófok lelóhelycédula az adriai tengerparttól a Balatonig terjedő hatalmas területen belül bármire vonatkozhat.

A Somogy megyéból jelenleg ismert 261 futóbogárfaj (a hazai fauna 53\%-a) három, egymástól jellegében jól elkülönülő terület meglehetősen alapos feltárásán alapszik:

a/ A Drávától majdnem a Balatonig húzódó homokterület, melynek a nagy része a Belsô-Somoggyal esik egybe.

b/ A Dráva mente Órtilostól-Szentborbásig terjedő része, amelynek az északnyugati és délkeleti sarka egymástól meglehetôsen eltérô futóbogárfaunának ad otthont.

c/ A Zselic Somogy megyéhez tartozó területe. A megyében a futóbogarak szempontjából fehér foltot képez a Balaton déli partszegélye, valamint a külsố somogyi dombvidék.

A Somogy megyében eddig megtalált futóbogarak közül a fajok döntó többsége országszerte elóforduló faj. Ezen belül két nagyobb csoportot lehet megkülönböztetni: az egyik az állandóan nedves élóhelyekhez kötött, a másik pedig a szárazabbakhoz és ennek fajai a szántóföldi élőhelyekre is jellemzóek.

A ritka fajokból - az elterjedési és ökológiai szempontokat figyelembe véve a következó csoportok állíthatók fel: 
1/ a somogyi homokvidéken élók, melyek Észak-Európa homokos síkságaira jellemzóek: Carabus marginalis Fabricius, 1794, Bembidion doris (Panzer, 1797), Poecilus lepidus (Leske, 1785), Pterostichus aterrimus (Herbst, 1784), Platynus longiventris Mannerheim, 1825.

2/ A Kárpát-medencét körbefogó hegyvidéki területekre jellemzók, melyeknek reliktum populációi részben mocsaras területeken, részben közvetlen a Dráva parton és az ártéren, részben pedig az Órtilos-Zákány közötti dombvidék nedves völgyeiben élnek: Carabus nodulosus Creutzer, 1799, Notiophilus biguttatus (Fabricius, 1779), Elaphrus aureus Müller, 1821, Elaphrus cupreus Duftschmid, 1812, Epaphius secalis (Paykull, 1790), Bembidion azurescens H. Wagner, 1930, Bembidion elongatum (Dejean, 1831), Bembidion fasciolatum (Duftschmid, 1812), Bembidion foraminosum Sturm, 1825, Bembidion fulvipes Sturm, 1827, Bembidion gilvipes (Sturm, 1825), Bembidion guttula (Fabricius, 1792), Bembidion modestum (Fabricius, I801), Bembidion punctulatum Drapiez, 1821 , Bembidion pygmaeum (Fabricius, 1792), Bembidion subcostatum javurcovae Fassati, 1944, Bembidion starki (Schaum, 1860), Perileptus areolatus (Creutzer, 1799), Harpalus atratus Latreille, 1804, Harpalus tenebrosus Dejean, 1829, Pterostichus transversalis (Duftschmid, 1812), Amara curta Dejean, 1828.

3/ Atlantikus elterjedésúek, melyeknek fó elterjedési területe Észak-Afrikára és Nyugat-Európára esik: Bembidion clarki Dawson, 1949, Trechus obtusus Erichson, 1837, Acupalpus brunnipes (Sturm, 1825), Ophonus stictus (Stephens, 1828), Europhilus scitulus (Dejean, 1825).

4/ Mediterrán elterjedésú faj: Tachys haemorrhoidalis Ponza, 1805.

A listából a következô fajok rendkívüli hazai ritkaságuk, illetve csak az utóbbi évekbeni magyarországi felfedezésük miatt érdemelnek említést:

Carabus marginalis Fabricius, 1794. Ennek a Belsô-Somogy homokos, ritkás erdeire és erdószegélyeire jellemzô fajnak az állományai az utóbbi két évtizedben nagyon megritkultak. A Vörös Könyvben szereplő védett faj.

Carabus nodulosus Creutzer, 1799. Ezt a futóbogárfajt Somogy Megyében elöször Nattán Miklós amatôr lepkész és bogarász gyújtötte a Kaposvár melletti Nádasdi-erdố nedves völgyeiben. Azóta a Zselic somogyi részén, a nedvesebb völgyekból az 1960-as években több alkalommal elókerült. Élóhelyei nagyon veszélyeztetetté váltak az utóbbi két évtizedben az egyre növekvoó kiszáradás miatt.

Bembidion starki Schaum, 1860. Tudomásom szerint a Zselicben lévô Lipótfán, a volt vasúti ôrház melletti, általam gyúitött (mocsári talajból kitaposott) példánya az egyetlen ismert hazai előfordulása jelenleg is, ennek az Alpokban és annak nyúlványaiban élö ritka futóbogárfajnak.

Bembidion clarkii Dawson, 1949. Az elsố hazai példányát Lipótfa és Bánya települések közötti kisebb füzes avarjából rostáltam 1987 tavaszán. Azóta mindössze 3 baranyai füzesból került eló: Kölked, Cún, Felsôszentmárton.

Bembidion doris (Panzer, 1797). Első hazai példányait a barcsi borókásban gyújtöttem az 1970-es évek végén. Azóta csak a Boronka-melléki Tájvédelmi Körzetból, Potonyból, Révfaluból, Kétújfaluból és Szöcéról ismert Magyarországról.

Tachys haemorrhoidalis Ponza, 1805. Publikált hazai lelóhelye - a Barcsi Borókásból leközölt egyetlen példányán kívül - csak Nagyvarsányból (SzabolcsSzatmár-Bereg megye) ismert a Fauna Regni Hungariae adataként. Mediterrán 
elterjedésú faj, amely Marokkóban és Dél-Európában gyakori, közel százéves adatai - újabbak nélkül - Németországból és Ausztriából is ismertek.

Trechus obtusus Erichson, 1837. Magyarországi előfordulása barcsi borókásbeli hím példányok ivarszervi vizsgálata alapján csak 1989-ben vált ismertté. Ennek az atlantikus elterjedésú fajnak a jelenlegi adatai - a Magyar Természettudományi Múzeum teljes kárpátmedencei Trechus anyagának feldolgozása után - fóleg a Dél-Dunántúlra vonatkoznak. Az Alföldön csak a Béda-Karapancsa Tájvédelmi Körzetból ismert. Az utóbbi években bebizonyosodott, hogy a barcsi borókásban gyakoribb, mint az egyébként országszerte nagyon gyakori, hozzá külső morfológiájában erósen hasonló Trechus quadristriatus (Schrank, 1781).

Acupalpus brunnipes (Sturm, 1825). Atlantikus elterjedésú, a barcsi borókásban rostálással gyújtött egyetlen példány az egyetlen biztos hazai lelóhelye, mert az 1920-as években gyưjtött, Lichtneckert gyújteményböl származó példányok hazai gyújtóhelye bizonytalan.

Ophonus stictus Stephens, 1828. Ennek az atlantomediterrán elterjedésú fajnak a két Somogy megyei (barcsi borókás és Vízvár) lelőhelyén kivül a Jakabhegyról és annak déli elóteréból van néhány hazai adata.

Europhilus scitulus (Dejean, 1825). Atlantikus elterjedésú. Magyarországi lelóhelyei csak a Dráva mentéról és a Boronka-melléki Tájvédelmi Körzetból ismertek, 1992-ben közöltem első hazai adatát.

\section{Somogy megyéból ismert futóbogárfajok jegyzéke}

Cicindela arenaria Fuesslin, 1775 ssp. viennensis Schrank, 1781 - Horvatovich 1981, 1981/a, 1995, 1998.

Cicindela campestris Linnaeus, 1758 . Horvatovich 1990, 1992.

Cicindela germanica Linnaeus, 1758 Horvatovich 1981/a, 1995, 1998.

Cicindela hybrida Linnaeus, 1758 Horvatovich 1981/a, 1995.

Cicindela soluta Dejean, 1822 - Horvatovich 1981/a, 1995, 1998.

Calosoma inquisitor (Linnaeus, 1758) Horvatovich 1995, Bérces (megjelenés alatt).

Calosoma sycophanta (Linnaeus, 1758) . Horvatovich 1980, 1981/a, 1995.

Carabus cancellatus Illiger, 1798 ssp. emarginatus Duftschmid, 1812 - Horvatovich 1981/a, 1990, 1992, 1995, Bérces (megjelenés alatt).

Carabus convexus Fabricius, 1775 . Horvatovich 1981/a, 1992, 1995, 1998, Bérces (megjelenés alatt).

Carabus coriaceus Linnaeus, 1758 ssp. praeillyricus Szél 1994. - Horvatovich 1981/a, 1990, 1992, 1995, 1998, Bérces (megjelenés alatt).

Carabus granulatus Linnaeus, 1758 . Horvatovich 1978, 1981/a, 1990, 1992, 1995,
1998, Bérces (megjelenés alatt).

Carabus hortensis Linnaeus, 1758 Horvatovich 1980, 1981/a, 1992, 1992, 1995, Bérces (megjelenés alatt).

Carabus intricatus Linnaeus, 1761 -

Horvatovich 1990, 1992, 1995, 1998.

Carabus marginalis Fabricius, 1794 - Csiki

1946, Horvatovich 1978, 1981/a, 1992, 1995.

Carabus nemoralis O. F. Müller, 1764 -

Horvatovich 1990, 1992, 1995, 1998, Bérces (megjelenés alatt).

Carabus nodulosus Creutzer, 1799 .

Horvatovich 1990.

Carabus scheidleri praescheidleri Mandl, 1965 Horvatovich 1990.

Carabus ullrichi Germar, 1824 .

Horvatovich 1990, 1995, 1998.

Carabus violaceus Linnaeus, 1758 ssp. exasperatus Duftschmid, 1812 - Horvatovich 1978, 1981/a, 1990, 1992, 1995, 1998.

Cychrus caraboides (Linnaeus, 1758 Horvatovich 1978, 1981/a, 1990, 1995, 1998, Bérces (megjelenés alatt).

Leistus ferruguineus (Linnaeus, 1758) Horvatovich 1992, 1995.

Leistus piceus Frölich, 1799 - Horvatovich 1990, 1992, 1995, Bérces (megjelenés alatt). 
Leistus rufomarginatus (Duftschmid, 1812) -

Horvatovich 1990.

Nebria brevicollis (Fabricius, 1792) Horvatovich 1990), 1992, 1998, Bérces (megjelenés alati).

Notiophilus biguttatus (Fabricius, 1779) Horvatovich 1980, 1981/a, 1995.

Notiophilus palustris (Duftschmid, 1812) Horvatovich 1981/a, 1990, 1992, 1995, Bérces (megjelnés alatt).

Notiophilus rufipes Curtis, 1829).

Horvatovich 1978, 1981/a, 1995.

Omophron limbatum (Fabricius, 1776) -

Horvatovich 1981/a, 1992, 1995, 1998.

Elaphrus aureus Müller, 1821 - Horvatovich

1980, 1990.

Elaphrus cupreus Duftschmid, 1812 -

Horvatovich 1981/a, 1992, 1995, 1998.

Elaphrus riparius (Linnaeus, 1758) -

Horvatovich 1981/a, 1992, 1995, 1998.

Elaphrus uliginosus Fabricius 1792 .

Horvatovich 1992.

Loricera pilicornis (Fabricius, I775) -

Horvatovich 1981/a, 1990, 1992, 1995, 1998,

Bérces (megjelenés alatt).

Scarites terricola Bonelli, 1813

Horvatovich 1978.

Clivina collaris (Herbst, 1784)

Horvatovich 1990, 1995, 1998.

Clivina fossor (Linnaeus, 1758).

Horvatovich 1978, 1981/a, 1990, 1992, 1995, 1998.

Dyschirius aeneus (Dejean, 1825) -

Horvatovich 1978, 1981/a, 1990, 1995, 1998.

Dyschirius chalceus Erichson, 1837 .

Horvatovich 1978.

Dyschirius extensus Rutzeys - Horvatovich 1992.

Dyschirius globosus (Herbst, 1784) .

Horvatovich 1981/a, 1992, 1995, 1998, Bér-

ces (megjelenés alatt).

Dyschirius luedersi Wagner, 1915.

Horvatovich 1990.

Dyschirius nitidus (Dejean, 1825)

Horvatovich 1981/a, 1992, 1995, 1998.

Dyschirius politus (Dejean, 1825) .

Horvatovich 1992.

Dyschirius tristis Stephens, 1827

Horvatovich 1995.

Broscus cephalotes (Linnaeus, 1758) -

Horvatovich 1981/a, 1995.

Epaphius secalis (Paykull, 1790) .

Horvatovich 1990, 1992, 1998.

Trechus obtusus Erichson, 1837 -

Horvatovich 1989, 1990, 1992, 1995, 1998,

Bérces (megjelenés alatt).
Trechus pilisensis Csiki, 1917 - Horvatovich 1978, 1979, 1990, 1995, 1998.

Trechus quadristriatus (Schrank, 1781) -

Horvatovich 1990, 1998.

Lasiotrechus discus (Fabricius, 1792) -

Horvatovich 1992, 1995, 1998.

Tachys bistriatus (Duftschmid, 1812) -

Horvatovich 1981/a, 1990, 1995, 1998.

Tachys diobrachys bisbimaculatus Chevrolat I868 - Horvatovich 1998.

Tachys haemorrhoidalis Ponza, 1805 -

Horvatovich 1981, 1981/a, 1995.

Tachys parrulus (Dejean, 1831).

Horvatovich 1998.

Tachyta nana (Gyllenhal, 1810) -

Horvatovich 1978, 1980/a, 1990, 1995, 1998.

Bembidion articulatum (Panzer, 1796) -

Horvatovich 1981/a, 1990, 1992, 1995, 1998.

Bembidion assimile Gyllenhal, 1810 .

Horvatovich 1981/a, 1992, 1995, 1998.

Bembidion azurescens Dalla Torre, 1877 .

Horvatovich 1992, 1995, 1998.

Bembidion biguttatum (Fabricius, 1779) -

Horvatovich 1981/a, 1995.

Bembidion clarkii (Dawson, 1849) -

Horvatovich 1990.

Bembidion dalmatinum (Dejean, 1831) ssp.

latinum Netolitzky, 1911 - Horvatovich 1981/a, $1995,1998$.

Bembidion decorum (Panzer, 180I) -

Horvatovich 1998.

Bembidion dentellum Thunberg, 1787 -

Horvatovich 1978, 1981/a, 1990, 1992, 1995, 1998.

Bembidion doris (Panzer, 1797)

Horvatovich 1980, 1981/a, 1992, 1995.

Bembidion elongatum (Dejean, 1831) -

Horvatovich 1995.

Bembidion fasciolatum (Duftschmid, 1812).

Bembidion femoratum Sturm, (1825) -

Horvatovich 1982, 1992, 1995, 1998.

Bembidion foraminosum (Sturm, 1825) -

Horvatovich 1995.

Bembidion fulvipes (Sturm, 1827) -

Horvatovich 1995.

Bembidion fumigatum (Duftschmid, 1812) -

Horvatovich 1978, 1995, 1998.

Bembidion gilvipes (Sturm, 1825) -

Horvatovich 1995.

Bembidion guttula (Fabricius, 1792).

Horvatovich 1981/a, 1995.

Bembidion illigeri Netolitzky, 1914 -

Horvatovich 1981/a, 1990, 1992, 1995, 1998.

Bembidion inoptatum (Schaum, 1857) -

Horvatovich 1981/a, 1990, 1992, 1995. 
Bembidion lampros (Herbst, 1784) -

Horvatovich 1981/a, 1990, 1992, 1995, 1998,

Bérces (megjelenés alatt).

Bembidin laticolle (Duftschmid, 1812) -

Horvatovich 1978.

Bembidion lunatum (Duftschmid, 1812) .

Horvatovich 1981/a, 1995.

Bembidion lunulatum (Fourcroy, 1785) -

Horvatovich 1998.

Bembidion minimum (Fabricius, 1792) -

Horvatovich 19981/a, 1995.

Bembidion modestum (Fabricius, 1801) -

Horvatovich 1998.

Bembidion octomaculatum (Goeze, 1777) -

Horvatovich 1981/a, 1992, 1995, 1998.

Bembidion properans (Stephens, 1828) -

Horvatovich 1978, 1981/a, 1992, 1995, 1998.

Bembidion punctulatum Drapiez, 1821 .

Horvatovich 1995, 1998.

Bembidion pygmaeum (Fabricius, 1792) .

Horvatovich 1978, 1998.

Bembidion quadrimaculatum (Linnaeus,

1761) - Horvatovich 1981/a, 1990, 1995, 1998.

Bembidion quadripustulatum Audinet-

Serville, 1821 - Horvatovich 1981/a, 1992, 1995.

Bembidion semipunctatum (Donovan, 1806) -

Horvatovich 1981/a, 1995, 1998.

Bembidion subcostatum javurcovae Fassati,

1944 - Horvatovich 1998.

Bembidion tenellum (Erichson, 1837) -

Horvatovich 1981/a, 1992, 1995, 1998.

Bembidion starki Schaum, I860 -

Horvatovich 1990.

Bembidion tetracolum (Say, 1823) .

Horvatovich 1995.

Bembidion varium (Olivier, 1795) -

Horvatovich 1978, 1981/a, 1992, 1995, 1998.

Asaphidion flavipes (Linnaeus, 1761) .

Horvatovich 1978, 1981/a, 1990, 1992, 1995, 1998.

Perileptus areolatus (Creutzer, 1799).

Horvatovich 1998.

Patrobus atrorufus (Szroem, 1768).

Horvatovich 1979, Bérces, (megjelenés alatt).

Perigona nigriceps (Dejean, 1831) .

Horvatovich 1980, 1981/a, 1995.

Anisodactylus binotatus (Fabricius, 1787) -

Horvatovich 1981/a, 1990, 1992, 1995, Bérces

(megjelenés alatt).

Anisodactylus signatus (Panzer, 1797).

Horvatovich 1978, 1981/a, 1990, 1992, 1995,

1998, Bérces (megjelenés alatt).

Diachromus germanus (Linnaeus, 1758) -

Horvatovich 1981/a, 1990, 1992, 1995.

Parophonus dejeani Csiki, 1932

Horvatovich 1998.
Parophonus maculicornis (Duftschmid, 1812) -

Horvatovich 1995, 1998.

Ophonun azureus (Fabricius, 1775) -

Horvatovich 1995, 1998.

Ophonus diffinis (Dejean, 1829).

Horvatovich 1998.

Ophonus melletii (Heer, 1837) -

Horvatovich, 1995, 1998.

Ophonus nitidulus Stephens, 1828.

Horvatovich 1992, 1995.

Ophonus puncticeps (Stephens, 1828) -

Horvatovich 1990, 1992, 1995, 1998.

Ophonus puncticollis (Paykull, 1798) -

Horvatovich 1992, 1995, 1998.

Ophonus rufibarbis (Fabricius, 1792) -

Horvatovich 1981/a, 1992, 1995, 1998.

Ophonus rupicola (Sturm 1818) -

Horvatovich 1990, Horvatovich 1992, 1998.

Ophonus signaticornis (Duftschmid, 1812) -

Horvatovich 1978.

Ophonus stictus (Stephens, 1828) -

Horvatovich 1981/a, 1995.

Pseudophonus calceatus (Duftschmid, 1812) -

Horvatovich 1992, 1995.

Pseudophonus griseus (Panzer, 1797) -

Horvatovich 1978, 1981/a, 1992, 1995, 1998.

Pseudophonus rufipes (De Geer, 1774) -

Horvatovich 1981/a, 1990, 1992, 1995, 1998,

Bérces (megjelenés alatt).

Harpalus affinis (Schrank, 1781) -

Horvatovich 1978, 1992, 1995, 1998.

Harpalus anxius (Duftschmid, 1812) -

Horvatovich 1981/a, 1992, 1995, 1998.

Harpalus atratus Latreille, 1804

Horvatovich 1995, 1998.

Harpalus autumnalis (Duftschmid 1812) -

Horvatovich 1981/a, 1992, 1995.

Harpalus dimidiatus (Rossi, 1790) -

Horvatovich 1995.

Harpalus distinguendus (Duftschmid, 1812) Horvatovich 1981/a, 1995, 1998.

Harpalus flavicornis Dejean, 1829 -

Horvatovich 1995.

Harpalus froelichi Sturm, 1818 .

Horvatovich 1981/a, 1992, 1995, 1998.

Harpalus luteicornis (Duftschmid, 1812) -

Horvatovich 1998.

Harpalus marginellus Dejean, 1829 -

Horvatovich 1990, 1992, 1995, 1998, Bérces

(megjelenés alatt).

Harpalus picipennis (Duftschmid, 1812 -

Horvatovich 1978, 1981/a, 1992, 1995, 1998.

Harpalus politus Dejean, 1829 .

Horvatovich 1980. 
Harpalus progrediens Schauberger, 1922 Horvatovich 1998.

Harpalus rubripes (Duftschmid, 1812) Horvatovich 1981/a, 1998.

Harpalus serripes (Quensel, 1806)

Horvatovich 1990, 1992, 1998.

Harpalus servus (Duftschmid, 1812 .

Horvatovich 1978, 1981/a, 1992, 1995.

Harpalus smaragdinus (Duftschmid, 1812) -

Horvatovich 1981/a, 1992, 1995.

Harpalus tardus (Panzer, 1797) -

Horvatovich 1981/a, 1990, 1992, 1995, 1998.

Harpalus tenebrosus Dejean, 1829 -

Horvatovich 1992, 1995.

Stenolophus discophorus Fischer, 1824 -

Horvatovich 1978, 1981/a, 1992, 1995, 1998.

Stenolophus mixtus (Herbst, 1784) -

Horvatovich 1978, 1981/a, 1992, 1995, 1998.

Stenolophus skrimshiranus Stephens 1828 -

Horvatovich 1981/a, 1992, 1995, 1998.

Stenolophus teutonus (Schrank, 178I)

Horvatovich 1981/a, 1992, 1995, 1998.

Amblystomus niger Hexr, 1838 - Horvatovich 1992.

Bradycellus harpalinus (Audinet-Serville,

1821) - Horvatovich 1981/a, 1990, 1992, 1995.

Bradycellus perbasci (Duftschmid, 1812) -

Horvatovich 1982, 1990), 1992, 1995, 1998. Acupalpus brunnipes (Sturm, 1825)

Horvatovich 1981, 1981/a, 1995.

Acupalpus dubius Schilsky, 1888

Horvatovich 1992, 1995, 1998.

Acupalpus exiguus (Dejean, 1829) -

Horvatovich 1981/a, 1990, 1992, 1995, 1998. Acupalpus flavicollis (Sturm, 1825) -

Horvatovich 1981/a, 1990, 1995.

Acupalpus luteatus (Duftschmid, 1812) -

Horvatovich 1981/a, 1995, 1998.

Acupalpus maculatus Schaum 1860 -

Horvatovich 1978, 1981/a, 1990, 1992, 1998. Acupalpus parvulus (Sturm, 1825)

Horvatovich 1978, 1981/a, 1992, 1995.

Anthracus consputus (Duftschmid, 1812) -

Horvatovich 1981/a, 1990, 1992, 1995, 1998.

Anthracus longicornis (Schaum, 1857).

Horvatovich 1978, 1981/a, 1995.

Stomis pumicatus (Panzer, 1796).

Horvatovich 1978, 1981/a, 1990, 1992, 1995,

1998, Bérces (megjelenés alau).

Poecilus cupreus (Linnaeus, 1758) -

Horvatovich 1981/a, 1990, 1992, 1995, 1998,

Bérces (megjelenés alatt).

Poecilus lepidus (Leske, 1785) - 1978, $1981 / \mathrm{a}, 1995$

Poecilus sericeus Fischer, $1824-1978$.

Poecilus versicolor (Sturm, 1824)
Horvatovich 1978, 1981/a, 1990, 1992, 1995, 1998, Bérces (megjelenés alatt).

Pterostichus anthracinus (Illiger, 1798) -

Horvatovich 1981/a, 1990, 1992, 1995, Bérces

(megjelenés alatt).

Pterostichus aterrimus (Herbst, 1784) -

Horvatovich 1981, 1981/a, 1995.

Pterostichus brunneus (Sturm, 1824) -

Horvatovich 1981/a, 1990, 1995, 1998.

Pterostichus cursor (Dejean, I828)

Horvatovich 1990.

Pterostichus diligens (Sturm, 1824) -

Horvatovich 1981/a, 1990, 1995.

Pterostichus guentheri (Sturm, 1824) -

Horvatovich 1981/a, 1995.

Pterostichus melanarius (Illiger, 1798) -

Horvatovich 1981/a, 1990, 1992, 1995, 1998,

Bérces (megjelenés alatt).

Pterostichus melas (Creutzer, 1799) -

Horvatovich 1990, 1995, 1998.

Pterostichus niger (Schaller, 1783) -

Horvatovich 1978, 1981/a, 1990, 1992, 1995,

1998, Bérces (megjelenés alatt).

Pterostichus nigrita (Fabricius, 1792) -

1981/a, 1992, 1995, Bérces (megjelenés alatt).

Pterostichus oblongopunctatus (Fabricius, 1787) - Horvatovich 1978, 1981/a, 1992,

1995, 1998, Bérces (megjelenés alatt).

Pterostichus ovoideus (Sturm, 1824) .

Horvatovich 1981/a, 1990, 1992, 1995, 1998,

Bérces (megjelenés alatt).

Pterostichus strenuus (Panzer, 1797) Horvatovich 1981/a, 1990, 1992, 1995, 1998, Bérces (megjelenés alatt).

Pterostichus transversalis (Duftschmid, 1812) Horvatovich 1995.

Pterostichus pernalis (Panzer, I796) Horvatovich 1978, 1981/a, 1990, 1995, Bérces (megjelenés alatt).

Abax carinatus (Duftschmid, 1812) -

Horvatovich 1978, 1981/a, 1990, 1992, 1995,

1998, Bérces (megjelenés alatt).

Abax parallelepipedus Piller et Mitterpacher, $1783-1978,1990,1992,1995$.

Abax parallelus Duftschmid 1812 -

Horvatovich 1990, 1992, 1998, Bérces (megjelenés alatt).

Synuchus pivalis (llliger, 1798) -

Horvatovich 1998.

Calathus erratus (Sahlberg, 1827) -

Horvatovich 1981/a, 1995, 1998.

Calathus fuscipes (Goeze, 1777) -

Horvatovich 1978, 1981/a, 1995, 1998.

Calathus melanocephalus (Linnaeus, 1758) -

Horvatovich 1981/a, 1995, 1998. 
Calathus ochropterus Duftschmid, 1812 . Horvatovich 1998.

Dolichus halensis (Schaller, 1783) Horvatovich 1978, 1981/a, 1990, 1995, 1998. Platyderes rufus (Duftschmid, 1812) Horvatovich 1978, 1981/a, 1990, 1995, 1998. Agonum angustatum Dejean, 1828 . Horvatovich 1992, 1998, Bérces (megjelenés alatt). Agonum atratum (Duftschmid, 1812) Horvatovich 1981/a, 1995.

Agonum duftschmidi Schmidt, I994. Horvatovich 1998.

Agonum gracilipes (Duftschmid, 1812) -

Horvatovich 1981/a, 1995.

Agonum longicorne Chaudoir, 1846.

Horvatovich 1995, 1998, Bérces (megjelenés alatt). Agonum lugens (Duftschmid, 1812) -

Horvatovich 1981/a, 1992, 1995, 1998. Agonum marginatum (Linnaeus, 1758) -

Horvatovich 1981/a, 1995.

Agonum moestum (Duftschmid, 1812) -

Horvatovich 1990, 1992, 1995, 1998, Bérces (megjelenés alatt).

Agonum obscurum (Herbst, 1784) -

Horvatovich 1978, 1981/a, 1990, 1992, 1995.

Bérces (megjelenés alatt).

Agonum permoestum Puel, 1938 .

Horvatovich 1992, 1995, 1998.

Agonum sexpunctatum (Linnaeus, 1758) -

Horvatovich 1981/a, 1992, 1995, Bérces (megjelenés alatt).

Agonum persutum Sturm, 1824 .

Horvatovich 1981/a, 1995.

Agonum piduum (Panzer, 1787

Horvatovich 1981/a, 1990, 1992, 1995.

Agonum piridicupreum (Goeze, 1777) .

Horvatovich 1978, 1981/a, 1995.

Platynus assimilis (Paykull, 1790).

Horvatovich 1981/a, 1990, 1992, 1995, 1998 ,

Bérces, (megjelenés alatt).

Platynus dorsalis (Pontoppidan, 1763) .

Horvatovich 1990, 1995, 1998.

Platynus krynickii (Sperk, 1835).

Horvatovich 1981/a, 1992, 1995, 1998, Bérces

(megjelenés alatt).

Platynus livens (Gyllenhal, 1810).

Horvatovich 1981/a, 1990, 1992, 1995, 1998.

Platynus longiventris Mannerheim, 1825 -

Horvatovich 1980, 1998.

Europhilus fuliginosus (Panzer, 1809) .

Horvatovich 1995, 1998.

Europhilus gracilis (Sturm, 1824) - 1981,

$1981 /$ a, 1995.

Europhilus micans (Nicolai, 1822) -

Horvatovich 1981/a, 1995, 1998.
Europhilus piceus (Linnaeus, 1758).

Horvatovich 1981/a, 1995.

Europhilus scitulus (Dejean, 1828) .

Horvatovich 1992, 1995, 1998.

Europhilus thorey (Dejean, 1828) -

Horvatovich 1981/a, 1992, 1995, 1998.

Amara aenea (De Geer 1774) - Horvatovich 1978, 1992, 1998.

Amara anthobia A. Villa et J. B. Villa, 1833

Horvatovich 1981/a, 1995, 1998.

Amara apricaria Paykull 1790 - Horvatovich 1992.

Amara aulica (Panzer, 1797) - Horvatovich

1978, 1981/a, 1995, 1998.

Amara bifrons (Gyllenhal, 1810) -

Horvatovich 1981/a, 1992, 1995, 1998.

Amara communis (Panzer, 1797)

Horvatovich 1981/a, 1992, 1995, 1998.

Amara consularis (Duftschmid, 1812) .

Horvatovich 1978, 1981/a, 1992, 1995.

Amara convexior Stephens, 1828.

Horvatovich 1990, 1992, 1995, 1998.

Amara curta Dejean 1828 - Horvalovich 1992.

Amara equestris (Duftschmid, 1812).

Horvatovich 1981, 1981/a, 1995.

Amara familiaris (Duftschmid, 1812) -

Horvatovich 1981/a, 1990, 1992, 1995, 1998. Amara gebleri Dejean, 1831 - Horvatovich 1998. Amara lucida Duftschmid, 1812 .

Horvatovich 1998.

Amara majuscula Chaudoir, 1850 -

Horvatovich 1992, 1995, 1998.

Amara orata (Fabricius 1792)

Horvatovich 1992, 1998.

Amara plebeja (Gyllenhal, 1810)

Horvatovich 1981/a, 1995, 1998.

Amara saphyrea Dejean 1828 -Horvatovich

1978, 1992, 1998.

Amara similata (Gyllenhal, 1810) -

Horvatovich 1978, 1981/a, 1990, 1992, 1995, 1990. Amara tricuspidata Dejean, 1831.

Horvatovich 1978, 1981/a, 1992, 1995, 1998. Chlaenius festivus (Panzer, 1796) -

Horvatovich 1981/a, 1995.

Chlaenius nigricomis (Fabricius, 1787) -

Horvatovich 1998.

Chlaenius nitidulus (Schrank, 1781) -

Horvatovich 1998.

Chlaenius spoliatus (Rossi, 1790) -

Horvatovich 1981/a, 1995, 1998.

Chlaenius tristis (Schaller, 1783) -

Horvatovich 1978, 1981/a, 1990, 1995, 1998. Chlaenius vestitus (Paykull, 1790) -

Horvatovich 1978, 1981/a, 1992, 1995, 1998.

Oodes gracilis A. Villa et B. Villa, 1833 -

Horvatovich 1998. 
Oodes helopioides (Fabricius, 1792) Horvatovich 1981/a, 1992, 1995, 1998, Bérces (megjolenés alatt).

Badister anomalus (Perris, 1866) Horvatovich 1992, 1995, 1998.

Badister bullatus (Schrank, 1798). Horvatovich 1995.

Badister dilatatus (Chaudoir, 1837). Horvatovich 1981/a, 1992, 1995, 1998.

Badister lacertosus Sturm, 1815. Horvatovich 1978, 1981/a, 1995, Bérces (megjelenés alatt).

Badister meridionalis Puel, 1925 . Horvatovich 1978, 1981/a, 1990, 1992, 1995, 1998.

Badister peltatus (Panzer, 1797) Horvatovich 1981/a, 1992, 1995, 1998.

Badister sodalis (Duftschmid, 1812) Horvatovich 1981/a, 1995.

Badister unipustulatus Bonelli, 1813 Horvatovich 1978, 1981/a, 1990, 1992, 1995, 1998.

Panagaeus crux-major (Linnaeus, 1758) Horvatovich 1981/a, 1995, 1998.

Odacantha melanura (Linnaeus, 1767) Horvatovich 1981/a, 1995.

Masoreus wetterhali (Gyllenhal, 1813) Horvatovich 1995.

Lebia chlorocephala (Hoffmann, 1803) Horvatovich 1981/a, 1990, 1995, 1998, Bérces (megjelenés alatt).

Lebia cruxminor (Linnaeus, 1758) Horvatovich 1981/a, 1995, 1998.

Demetrias atricapillus (Linnaeus, 1758) -
Horvatovich 1981/a, 1990, 1992, 1995, 1998. Demetrias imperialis (Germar, 1824) -

Horvatovich 1981/a, 1995.

Demetrias monostigma Samouelle, 1819) -

Horvatovich 1978, 1981/a, 1990, 1995, 1998. Dromius agilis (Fabricius, 1787)

Horvatovich 1981/a, 1995. Dromius linearis (Olivier, 1795)

Horvatovich 1990, 1998. Dromius quadrimaculatus (Linnaeus, 1758) Horvatovich 1998.

Dromius sigma (Rossi, 1790) - Horvatovich 1981/a, 1992, 1995, 1998.

Syntomus foreatus (Fourcroy, 1785) -

Horvatovich 1979, 1980, 1981/a, 1995.

Syntomus obscuroguttatus (Duftschmid, 1812) - Horvatovich 1981/a, 1992, 1995, 1998.

Syntomus pallipes (Dejean, 1825).

Horvatovich 1981/a, 1990, 1995, 1998.

Syntomus truncatellus (Linnaeus, 1761) -

Horvatovich 1981/a, 1990, 1995.

Lionychus quadrillum (Duftschmid, 1812) -

Horvatovich 1998. Microlestes maurus (Sturm, 1827) -

Horvatovich 1992, 1998. Microlestes minutulus (Goeze, 1777) -

Horvatovich 1992, 1998.

Drypta dentata (Rossi, 1790) - Horvatovich I990, 1992, 1998.

Brachinus explodens Duftschmid, 1812 Horvatovich I990, 1998.

Brachinus ganglbaueri (Apfelbeck, 1904) Horvatovich 1990.

\section{Irodalom}

BÉrCES, S. (megjelenés alatt): \datok a Baláta-tavi Természetvédelmi Terület futóbogárfaunájához (Coleoptera: Carabidae).

CsıKı, E. 1946: Die Kaferfauna des Karpaten-Beckens - Naturwissenschaftliche Monographien IV: $79-546$.

Horvatovich, S. 1978: Adatok Dél-Dunántúl bogárfaunájához I. (Coleoptera: Cicindelidae, Carabidae). - A Janus Pannonius Múzeum Évkönyve, 22:45-55.

Horvatovich, S. 1979: Hazánk faunájára új és ritka bogárfajok a Dél-és Nyugat-1)unántúlról (Coleoptera) - A Janus P’annonius Múzeum Évkönyve 23: 31 -39.

Horvntovich, S. 1980: Hazánk faunájára új és ritka bogárfajok a Dél- és Nyugat-Dunántúlról II. - A Janus Pannonius Múzeum Évkönyve 24: 33-43.

Horvatovich, S. 1981: Hazánk faunájára új és ritka bogárfajok a Dél- és Nyugat-Dunántúlról III. - A Janus P’annonius Múzeum Évkönyve 25: $71-83$.

Horvatovich, S. 1981/a: ^ Barcsi Borókás Tájvédelmi Körzet cicindelidái, carabidái és dytiscidái (Coleoptera) - Dunántúli Dolgozatok Természettudományi Sorozat, 2: 65-79.

Horv^tovich, S. 1982: Hazánk faunájára új és ritka bogárfajok a Dél- és Nyugat-Dunántúlról IV. - A Janus Pannonius Múzeum Évkönyve 26: 19-32.

Horvniovich, S. 1989: Über die Verbreitung und die Biotope von Trechus obtusus Erichson, 1837 (Coleoptera: Carabidae) in Ungarn - Fol. ent. hung. 50: 19-22. 
Honvarovich, S. 1990: $\Lambda$ Zselic futóbogarai (Colcoptera: Carabidae) - $\Lambda$ Janus Pannonius Múzcun Évkönyve 34: 5-14.

Horvarovich, S. 1992: ^ Boronka-melléki Tájvédelmi Körzct futóbogarai és állasbogarai (Coleoptera: Carabidae, Rhysodidac) - Dunántúli Dolgozatok Természettudományi Sorozat 7: 127-148.

Horvatovich, S. 1993: Liste der Carabiden-Arten (Coleoptera: Carabidac) Ungarns (Stand 1991) - $\Lambda$ Janus Pannonius Múzeum Évkönyve, 37: 5-12.

Horvarovich, S. 1995: A Dráva mente futóbogár (Coleoptera: Carabidae) faunájának alapvetése - Dunántúli Dolgozatok Természettudományi Sorozat 8: 73-84.

Horvatovich, S. 1998: A Dráva mente futóbogár (Colcoptera: Carabidac) faunája II. - Dunántúli Dolgozatok 'Természetudományi Sorozat 9: 177-187.

\section{Catalogue of the carabid beetles (Coleoptera: Carabidae) of Somogy county}

\section{SÁNDOR HORVATOVICH}

However 261 carabid species are known from Somogy county at present, the first data (Carabus marginalis) were published only, in 1946. The majority of dates concern three well investigated areas (the Dráva region, the Boronka region and the Zselic Hills). The Balaton region and the downs of Külsó Somogy are almost uninvestigated.

The greater part of species is generally distributed in Hungary. The bulk of this group lives in wet habitats. The rest of species prefers drier habitats and are generally distributed in the arable soils of Hungary.

The rare species are divided into the following groups:

1/ Stenotopic species living in the sandy region of Somogy county, distributed mainly in Siberia: Carabus marginalis, Bembidion doris, Poecilus lepidus, Pterostichus aterrimus, Platynus longiventris.

2/ Species of Carpathians and Alps. These species live in Somogy County in the marshes, on the riversides of Dráva and on the Órtilos down: Carabus nodulosus, Notiophilus biguttatus, Elaphrus aureus, Elaphrus cupreus, Epaphius secalis, Bembidion azurescens, Bembidion elongatum, Bembidion fasciolatum, Bembidion foraminosum, Bembidion fulvipes, Bembidion gilvipes, Bembidion guttula, Bembidion modestum, Bembidion punctulatum, Bembidion pygmaeum, Bembidion subcostatum janurcovae, Bembidion starki, Perileptus areolatus, Harpalus atratus, Harpalus tenebrosus, Pterostichus transversalis, Amara curta.

3/ Species having their main distribution in Western Europe: Bembidion clarkii, Trechus obtusus, Acupalpus brunnipes, Ophonus stictus, Europhilus scitulus.

4/ Mediterranean species: Tachys haemorrhoidalis.

Author's address:

Dr. Sándor HoRvNTOVICH

Janus Pannonius Múzeum

H-7622 Pécs

Szabadság út 2. Po Box: 347

HUNGARY 